\title{
Detection of epitopes in systemic lupus erythematosus using peptide microarray
}

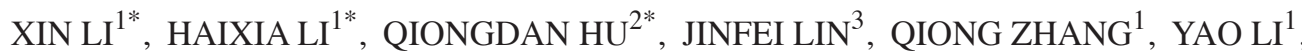

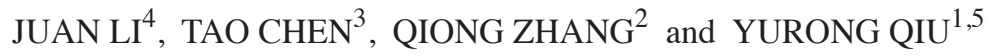 \\ ${ }^{1}$ Clinical Laboratory of Nanfang Hospital, Southern Medical University, Guangzhou, Guangdong 510515; \\ ${ }^{2}$ Department of Nephrology, The Traditional Chinese Medicine Hospital, Affiliated to Southwest Medical University, Luzhou, \\ Sichuan 646000; ${ }^{3}$ South China Institute of Microbial Ecology and Health; ${ }^{4}$ Department of Rheumatology, Nanfang Hospital; \\ ${ }^{5}$ Guangdong Key Laboratory of Biochip Technology, Southern Medical University, \\ Guangzhou, Guangdong 510515, P.R. China
}

Received September 14, 2017; Accepted January 19, 2018

DOI: $10.3892 / \mathrm{mmr} .2018 .8710$

\begin{abstract}
Systemic lupus erythematosus (SLE) is a common autoimmune disease, which features the secretion of antibodies directed against autoantigens in vivo. In the present study, a peptide microarray was developed to detect the epitopes recognized by autoantibodies in patients with SLE for an effective method of diagnosis. SLE-associated epitopes in 14 autoantigens were predicted using the antigenic epitope prediction software DNA star. Peptides were synthesized based on the predicted antigenic epitopes and immobilized on a slide surface and developed into a peptide microarray. Using this peptide microarray the autoantibodies in 120 patients with SLE and 110 healthy subjects were detected. A total of 73 potential antigenic epitopes in 14 autoantigens were predicted and screened. The peptide microarray based on the 73 epitopes was used to detect the autoantibodies in patients with SLE. A total of 14 epitopes with potential diagnostic values were screened out. The sensitivity and specificity of the 14 epitopes for the diagnosis of SLE were 71.6 and 85.8\%, respectively. An optimal set of epitopes for SLE diagnosis was obtained. As individual patients had a specific autoantibody spectrum it was possible to detect autoantibodies in SLE and perform the diagnosis of SLE using the peptide microarray.
\end{abstract}

Correspondence to: Professor Yurong Qiu, Clinical Laboratory of Nanfang Hospital, Southern Medical University, 1838 North Guangzhou Avenue, Guangzhou, Guangdong 510515, P.R. China E-mail: qiuyuronggz@126.com

Dr Qiong Zhang, Department of Nephrology, The Traditional Chinese Medicine Hospital, Affiliated to Southwest Medical University, 182 Chunhui Road, Luzhou, Sichuan 646000, P.R. China E-mail: lyjean69@163.com

*Contributed equally

Key words: autoimmune disease, systemic lupus erythematosus, autoantibody, epitope, peptide microarray

\section{Introduction}

Systemic lupus erythematosus (SLE) is one of the common autoimmune diseases, mostly occurs in Asian women. The main cause of this disease is that the autoimmune system attacks its own tissues, resulting in tissue damage (1-3). The typical symptoms of SEL include specific lesions with butterfly erythema, subacute skin lupus erythematosus and discoid erythema, and non-specific lesions with light allergy, hair loss, mouth ulcers, skin vasculitis (purpura), pigmentation or depigmentation, livedo reticularis, Raynaud's phenomenon, urticaria-like rash and rare lupus lipid film Inflammation or deep lupus and bullous lupus erythematosus (4). Numerous studies have shown that the abnormalities in genetic, endocrine, infection, immune and some environmental factors are associated with the incidence of SLE $(3,5)$. However, the pathogenesis of SLE has not yet been elucidated.

The main pathological manifestation of autoimmune diseases is that the patient produces a high level of autoantibodies to identify different autoantigens. It was demonstrated that autoantibodies associated to several autoantigens and involved in SLE including anti-double stranded antibody (anti-dsDNA antibody), anti-nuclear antibody (ANA), anti-soluble antigen antibodies (anti-ENA antibody) including anti-Jo-1, anti-U1RNP antibody (anti-nRNP antibody), anti-ribosomal P antibody (anti-rRNR antibody), anti-Scl-70, anti-Sm antibody, anti-SSA/Ro antibody and anti-SSB/La antibody, anti-nucleosome antibodies, and anti-phospholipid antibodies (6-12). The use of autoantigens to detect autoantibodies is an important technique for the diagnosis of autoimmune diseases. However, the intact autoantigen profiling is difficult to obtain and purify, and the stability of the antigens is poor. In order to avoid the high production cost and poor stability of autoantigens, some attempts have been made to detect autoantibodies by alternative. To achieve the goal of diagnosis, some studies have been attempted to detect the autoantibodies in SLE using protein chip (13-17). However, the protein chip is also limited by the difficult in expression and purification the intact antigens. Researchers try to find a more desirable alternative such as peptide microarray. 
In recent years, peptide microarray has been developed rapidly (18-20). Peptide microarrays integrate many peptide active molecules on a very small surface area, so as to detect the expression and function of different biomolecules (21). Peptide microarrays has advantages in simple and fast, high-throughput and accuracy, and low-cost, compared with traditional protein chips. Using peptide microarrays, the diagnostic accuracy of lung cancer indicators was $93.1 \%$ (22). The diagnostic accuracy of plasma in lung cancer patients using peptide microarrays was also reached $92 \%(23,24)$. It was also found that peptide microarrays are useful in the detection of p53 autoantibodies, and have potential application value in head and neck cancer patients $(25,26)$. However, thus far, the use of the peptide microarray technique in diagnosis of autoimmune diseases, particularly the early diagnosis of SLE have not been well studied yet.

In the present study, we predicted the SLE-related epitopes in 14 autoantigens using the antigenic epitope prediction software DNA star, and designed the peptide microarray for SLE detection. Then, the autoantibodies in 120 SLE patients and 110 healthy subjects were analyzed and an optimal set of epitopes were screened out. The sensitivity and specificity of the optimal set of epitopes in diagnosis of SLE were evaluated.

\section{Materials and methods}

Patients. Samples from 120 patients with SLE (including 15 males and 105 females, average age was 34.5 years) who underwent SLE treatment in the Southern China Hospital were collected. Samples from 110 healthy volunteers (including 15 males and 95 females, average age was 30.2 years) were also collected. There were no significant differences in the sex and age between the SLE patients and healthy subjects. The diagnostic criteria for SLE were acute or subacute cutaneous lupus manifestations, manifestations of chronic cutaneous lupus, arthritis, serositis, renal disorder, blood-hematologic diseases, oral or nasopharyngeal ulcers, immunological disorder, and alopecia. The diagnosis of SLE should include four of the above criteria, one clinical criterion and one immunological criterion. The immunological criteria were as follows: i) higher titers of ANA than the laboratory reference standard; ii) higher titers of anti-dsDNA than the laboratory reference standard; iii) positive anti-Sm antibody; iv) anti-phospholipid antibodies (positive anti-lupus anticoagulant/false positive serological test for syphilis/anticardiolipin antibody at twice the normal level or increased anti-B2GPI above titer); v) decreased level of complement proteins ( $\mathrm{C} 3, \mathrm{C} 4$ and $\mathrm{CH} 50)$; and vi) no hemolytic anemia, but Coombs test is positive. Renal disorder was confirmed as lupus nephritis (diagnosed by lupus nephritis with ANA or anti-dsDNA-positive). The exclusion criteria included patients with viral hepatitis, tuberculosis or SLE combined with other primary organ diseases. In the present study, we did not exclude the patients with other infections including influenza, EBV and HIV, because those infections in China are very low. All participants signed informed consent. The present study was approved by the Ethics Committee of Southern China Hospital.

Epitopes prediction by DNA star software. The DNA star (NIAID, USA) was used to predict the epitopes on
14 autoantigens. In the DNA STAR online analysis system, the parameters 'Epitope' and 'assay' were set as 'any epitopes' and 'all'. Followed by searching and querying, the parameters 'MHC Restriction', 'Host', and 'Disease' were set as 'any MHC Restriction', 'Humans', and 'Autoimmune Disease' for each antigen indicator. After further narrowed the search range by the peptide information and the linked literatures, we obtained the peptide sequences associated with SLE.

Peptide microarray preparation. All peptides (purity $>98 \%$ ) were synthesized by Sangon Biotech, Shanghai, China. The peptide indicators were prepared using a biochip spotting instrument (AD3200; BioDot, Irvine, CA, USA). The peptide microarray was prepared in a clean slide. After the peptide microarray was soaked in a 5\% ammonia silane anhydrous ethanol solution for $30 \mathrm{~min}$. After washed 3 times with anhydrous ethanol and deionized water for $5 \mathrm{~min}$, the peptide microarray was air-dried and soaked in a phosphate-buffer solution (PBS) containing 2.5\% glutaraldehyde for $30 \mathrm{~min}$. After washes with anhydrous ethanol and deionized water for $5 \mathrm{~min}$, three times, the peptide microarray (384-well plate) was prepared for peptide loading. The peptide was well-diluted to $0.5 \mathrm{mg} / \mathrm{ml}$ in PBS and loaded into the peptide microarray at $20 \mu \mathrm{l} / \mathrm{well}$. After centrifuged $2 \mathrm{~min}$ at 2,000 rpm, the peptide microarrays were placed overnight, stored in a slide box, and sealed within hermetic bags at $4^{\circ} \mathrm{C}$ (or $-20^{\circ} \mathrm{C}$ with humidity $<50 \%$ for long-term storage). The bags were exposed to room temperature for 3-4 $\mathrm{h}$ before pick out the peptide microarray.

Diagnosis of SLE by peptide microarray. For screening, the peptide microarray was blocked with $0.1 \%$ bovine serum albumin (BSA) in PBS for 30 min, incubated with serum specimens for $4 \mathrm{~h}$, followed by washes with PBS with Tween-20 5 times, and PBS 5 times. Then, the peptide microarray was incubated with a 555-Streptavidin fluorescein for $1 \mathrm{~h}$ at room temperature, and then washes with PBST and PBS 5 times, respectively. A biotinylated anti-human IgG was used for autoantibody detection. After air-drying, the peptide microarray was measured by Jingxin LuxScan ${ }^{\mathrm{TM}}$ 10K-B Microarray Scanners (CapitalBio Corporation, Beijing, China) with $532 \mathrm{~nm}$ excitation wavelength. Finally, data analysis was performed by GenePro software version 6 (GenePro, Fitchburg, WI, USA) and GraphPad Prism software version 6 (GraphPad Software, Inc., La Jolla, CA, USA).

ELISA detection. In order to verify the validity of epitopes, we selected the 2 most commonly used SLE autoantibodies in clinic including Sm, and RNP. A complete antigen of each indicator was used to detect the autoantibodies in sera of the SLE patients using the Human peripheral blood anti-Sm IgG (cat. no. EA1593-9601G) and anti-nRNP IgG (cat. no. EA1591-9601G) ELISA Kit (EUROIMMUN Medizinische Labordiagnostika AG, Lubeck, Germany) following the kit instruction. The cut-off value was $20 \mathrm{RU} / \mathrm{ml}$. The results of ELISA were compared with those of peptide microarray. For Sm, the peptides including SMD1-2, SMD2-1, SMD2-2 and SMD3-1 were compared; for RNP, the peptides including U1-SnrnpA-2 and U1-SnRNP 68/70 kDa were compared. 
Table I. Predicted epitopes on 14 antigens.

\begin{tabular}{|c|c|c|c|}
\hline Number & Start & End & Peptide \\
\hline \multicolumn{4}{|c|}{ SMD1 (Accession: CAE11897.1) } \\
\hline 1 & 83 & 119 & $\begin{array}{l}\text { VEPKVKSKKREAVAGRGRGRGR } \\
\text { GRGRGRGRGRGGPRR }\end{array}$ \\
\hline 2 & 41 & 57 & KAVKMTLKNREPVQLET \\
\hline 3 & 12 & 26 & HETVTIELK \\
\hline \multicolumn{4}{|c|}{ SMD2 (Accession: AAC13776.1) } \\
\hline 1 & 1 & 19 & MSLLNKPKSEMTPEELQKR \\
\hline 2 & 112 & 118 & NPLIAGK \\
\hline 3 & 76 & 90 & EVPKSGKGKKKSKPV \\
\hline 4 & 93 & 98 & DRYISK \\
\hline 5 & 22 & 27 & EEFNTG \\
\hline \multicolumn{4}{|c|}{ SMD3 (Accession: AAA57034.1) } \\
\hline 1 & 120 & 126 & NIFQKRR \\
\hline 2 & 110 & 117 & RGRGRGMG \\
\hline 3 & 43 & 61 & MSNITVTYRDGRVAQLEQV \\
\hline 4 & 96 & 108 & GRGKAAILKAQVA \\
\hline 5 & 32 & 39 & LIEAEDNM \\
\hline \multicolumn{4}{|c|}{ Proliferating cell nuclear antigen (PCNA) (Accession: NP_872590.1) } \\
\hline 1 & 253 & 261 & PKIEDEEGS \\
\hline 2 & 57 & 67 & FDTYRCDRNLA \\
\hline 3 & 149 & 157 & RDLSHIGDA \\
\hline 4 & 80 & 87 & KCAGNEDI \\
\hline 5 & 1 & 8 & MFEARLVQ \\
\hline \multicolumn{4}{|c|}{ Acidic ribosomal phosphoprotein (P1) (Accession: AAA36471.1) } \\
\hline 1 & 18 & 30 & DDEVTVTEDKINA \\
\hline \multicolumn{4}{|c|}{ Acidic ribosomal phosphoprotein (P2) (Accession: AAA36472.1) } \\
\hline 1 & 44 & 61 & SELNGKNIEDVIAQGIGK \\
\hline 2 & 12 & 18 & LGGNSSP \\
\hline \multicolumn{4}{|c|}{ snRNP-B/B' (Accession: P14678.2) } \\
\hline 1 & 1 & 11 & MTVGKSSKMLQ \\
\hline 2 & 48 & 66 & FRKIKPKNSKQAEREEKRV \\
\hline 3 & 90 & 99 & TGIARVPLAG \\
\hline 4 & 34 & 40 & FDKHMNL \\
\hline 5 & 70 & 78 & VLLRGENLV \\
\hline 6 & 223 & 231 & PPPGMRGPP \\
\hline 7 & 22 & 45 & LQDGRIFIGTFKAFDKHMNLILCD \\
\hline \multicolumn{4}{|c|}{ U1-snRNP-C (Accession: NP_003084.1) } \\
\hline 1 & 82 & 91 & SLPGPPRPGM \\
\hline 2 & 69 & 80 & APPPAGAMIPPP \\
\hline 3 & 35 & 47 & KDYYQKWMEEQAQ \\
\hline \multicolumn{4}{|c|}{ U1-snRNP-A (Accession: NP_004587.1) } \\
\hline 1 & 1 & 10 & MAVPETRPNH \\
\hline 2 & 60 & 77 & KEVSSATNALRSMQGFPF \\
\hline 3 & 94 & 104 & IAKMKGTFVER \\
\hline 4 & 80 & 91 & KPMRIQYAKTDS \\
\hline 5 & 94 & 104 & IAKMKGTFVER \\
\hline \multicolumn{4}{|c|}{ Nucleolin (Accession: AAA59954.1) } \\
\hline 1 & 118 & 127 & VATPGKKGA \\
\hline 2 & 214 & 233 & TPAKGKKAAK \\
\hline 3 & 315 & 327 & NFNKSAPELKTGI \\
\hline
\end{tabular}


Table I. Continued.

\begin{tabular}{|c|c|c|c|}
\hline Number & Start & End & Peptide \\
\hline 4 & 331 & 337 & FAKNDLA \\
\hline 5 & 347 & 353 & RKFGYVD \\
\hline 6 & 421 & 430 & LVSKDGKSKG \\
\hline 7 & 514 & 526 & VPQNQNGKSKGYA \\
\hline \multicolumn{4}{|c|}{ Acidic ribosomal phosphoprotein (P0) (Accession: AAA36470.1) } \\
\hline 1 & 1 & 13 & MPREDRATWKSNY \\
\hline 2 & 21 & 27 & LDDYPKC \\
\hline 3 & 32 & 41 & ADNVGSKQMQ \\
\hline 4 & 45 & 51 & MSLRGKA \\
\hline 5 & 91 & 100 & TKEDLTEIRD \\
\hline 6 & 125 & 136 & AQNTGLGPEKTS \\
\hline 7 & 146 & 152 & KISRGTI \\
\hline 8 & 162 & 171 & KTGDKVGASE \\
\hline 9 & 202 & 213 & EVLDITEETLH \\
\hline 10 & 215 & 220 & FLEGVR \\
\hline 11 & 243 & 249 & NGYKRVL \\
\hline 12 & 296 & 312 & AKVEAKEESEESDEDMG \\
\hline \multicolumn{4}{|c|}{ DNA topoisomerase1 (truncated) (Accession: NP_003277.1) } \\
\hline 1 & 52 & 66 & YDGKVMKLSPKAEEV \\
\hline 2 & 89 & 103 & FKDWRKEMTNEEKNI \\
\hline 3 & 1 & 12 & KKKKРКKEEEQK \\
\hline 4 & 128 & 136 & QMSKEEKLK \\
\hline 5 & 415 & 422 & LTAPDENI \\
\hline \multicolumn{4}{|c|}{ DNA topoisomerase 1 (full length) (Accession: NP_003277.1) } \\
\hline 1 & 459 & 476 & NQYREDWKSKEMKVRQRA \\
\hline 2 & 674 & 682 & VMKDAKTKK \\
\hline 3 & 491 & 498 & NEKEEGET \\
\hline 4 & 504 & 510 & CCSLRVE \\
\hline 5 & 365 & 376 & GNHPKMGMLKRR \\
\hline \multicolumn{4}{|c|}{ U1-SnRNP 68/70 KDa (Accession: P08621.2) } \\
\hline 1 & 424 & 437 & LAPENGYLMEAAPE \\
\hline 2 & 375 & 383 & DREHKRGER \\
\hline 3 & 120 & 134 & RREFEVYGPIKRIHM \\
\hline 4 & 282 & 294 & KDKDRDRKRRSSR \\
\hline 5 & 303 & 315 & RERKEELRGGGGD \\
\hline 6 & 1 & 8 & MTQFLPPN \\
\hline 7 & 211 & 217 & SGRDDTS \\
\hline 8 & 138 & 145 & KRSGKPRG \\
\hline
\end{tabular}

Statistical analysis. Peptide microarray data were measured using GenePro software version 6.0 (GenePro), and analyzed by GraphPad Prism software v 6.0 (GraphPad) using Student's t-test. The ROC curves and area calculated were performed by SPSS software version 16.0 (SPSS, Inc., Chicago, IL, USA). A value of $\mathrm{P}<0.05$ was considered statistically significant.

\section{Results}

Prediction of antigens. Using the DNA star software, a total of 73 potential epitopes were obtained from 14 autoantigens were predicted. The 14 autoantigens included acidic ribosomal phosphoprotein (P0), acidic ribosomal phosphoprotein (P1), acidic ribosomal phosphoprotein (P2), DNA topoisomerase 1 (full length 0, DNA topoisomerase 1 (truncated), nucleolin, proliferating cell nuclear antigen (PCNA), SMD1, SMD2, SMD3, snRNP-B/B', U1-snRNP 68/70 kDa, U1-snRNP-A, and U1-snRNP-C. The detailed information of the epitopes are shown in Table I.

Samples detection by peptide microarray. The peptide microarray based on the 73 epitopes were used to test the serum 

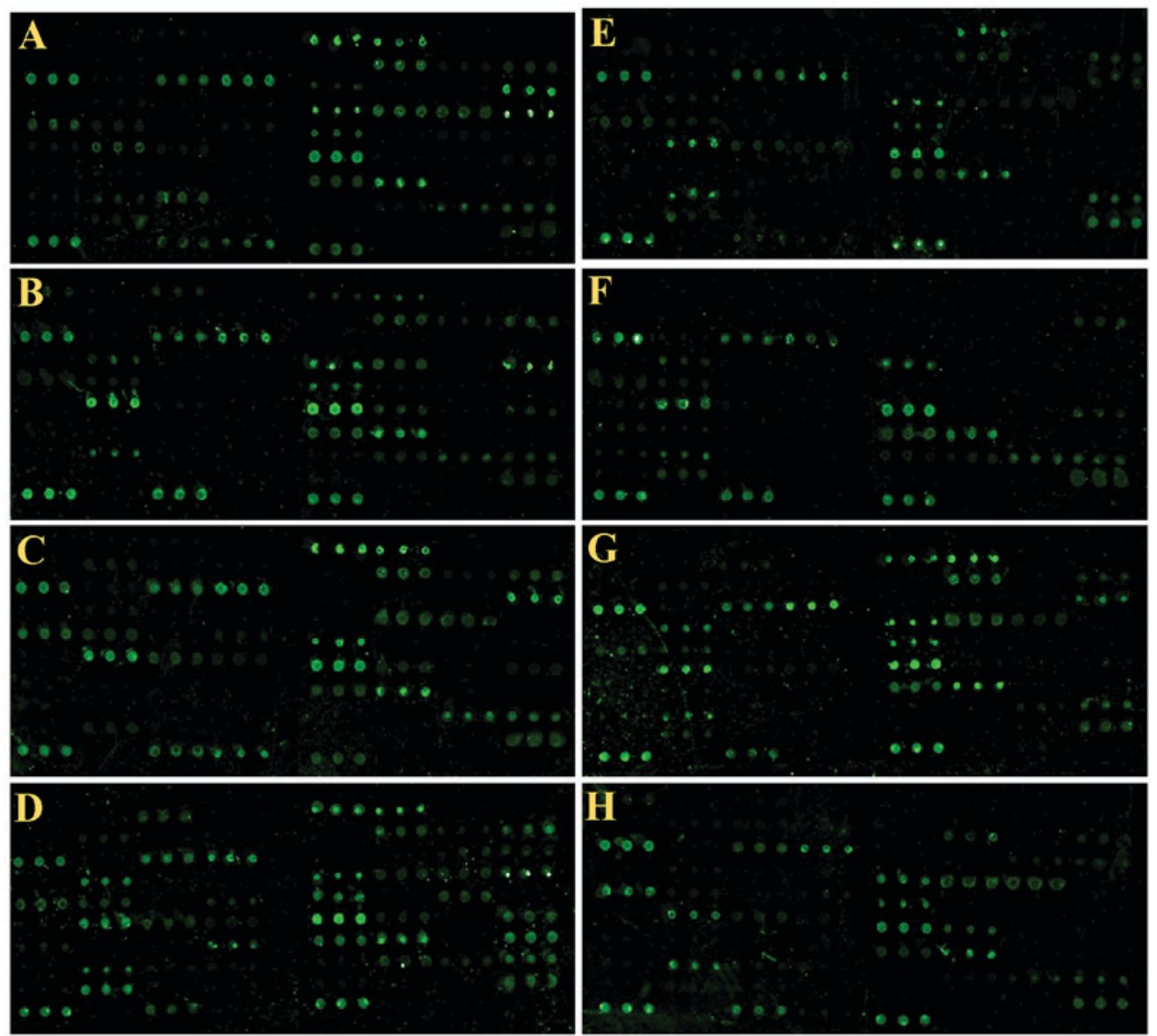

Figure 1. Representative peptide microarray detection data. (A-D) SLE patients. (E-H) healthy subjects.

autoantibodies in 120 SLE patients and 110 matched healthy subjects (Fig. 1).

The results showed that the autoantibodies that produced by different individuals recognized and bound different epitopes. If the signal information larger than the negative control, the average data plus 10 mines of SD was sued to assess the positive rate. The positive controls used in the present study was biotinylated random linear 12-peptide. The negative control was a random linear 12-peptide. We analyzed the positive rate and false positive rate of each peptide (Fig. 2). It can be seen there were 18 peptides had high positive rate with low false positive rate, including P0-2, P0-4, P2-1, SMD1-2, SMD2-1, SMD2-2, SMD3-1, PCNA-2, U1-SnrnpA-2, DNA (full length)-5, U1-68/70kDa-3, U1-68/70kDa-7, U1-68/70kDa-8, DNA (truncated)-1, DNA (truncated)-2, Nucleolin-1, Nucleolin-5, and Nucleolin-7. All the positive rate and false positive rate of the peptides were no less and no $>10 \%$, respectively. The ratio of positive rate to false positive rate was $>5$, indicating all the 18 peptides are valuable epitopes.

ROC curve plotting and area analysis. The specificity and 1-specificity of all cut-off points in data from the 18 screened peptides were calculated and the ROC curve was plotted (Fig. 3A). The areas under the ROC curves of peptides P0-2, P0-4, P2-1, SMD1-2, SMD2-1, SMD2-2, SMD3-1, PCNA-2, U1-SnrnpA-2, DNA (full length)-5, U1-68/20Da-3, U1-68/20kDa-7, U1-68/20kDa-8, DNA (truncated)-1, DNA (truncated)-2, Nucleolin-1, Nucleolin-5 and Nucleolin-7 was $0.662 \pm 0.051,0.622 \pm 0.053,0.498 \pm 0.054,0.701 \pm 0.050$, $0.760 \pm 0.045,0.756 \pm 0.050,0.713 \pm 0.049,0.704 \pm 0.049$, $0.550 \pm 0.054,0.691 \pm 0.050,0.685 \pm 0.050,0.689 \pm 0.050$, $0.795 \pm 0.042,0.707 \pm 0.050,0.639 \pm 0.052,0.684 \pm 0.051$, $0.651 \pm 0.053$, and $0.672 \pm 0.051$ (Fig. 3B). And the area under the curves of 14 peptides was $>0.65$, including P0-2, SMD1-2, SMD2-1, SMD2-2, SMD3-1, PCNA-2, DNA (full length)-5, U1-68/20kDa-3, U1-68/20kDa-7, U1-68/20kDa-8, DNA (truncated)-1, Nucleolin-1, Nucleolin-5 and Nucleolin-7, suggesting they are of significant diagnostic value in SLE.

Verification of the validity of epitopes. In order to verify the validity of the 14 epitopes, we selected the intact antigens of 2 most commonly used SLE autoantibodies in clinic, including Sm and RNP to detect the sera of the SLE patients using direct ELSIA kit. The results of ELISA were compared with those of peptide microarray (for $\mathrm{Sm}$, the peptides including SMD1-2, SMD2-1, SMD2-2 and SMD3-1 were compared; for RNP, the peptides including U1-SnrnpA-2 and U1-SnRNP $68 / 70 \mathrm{kDa}$ were compared) (Table II). When one peptide was positive, the results of peptide microarray was set as positive. The peptide microarray was higher in sensitivity and lower in specificity than the direct ELISA. In addition, when detected an expanded sample set including 120 SLE patients and 110 healthy subjects (Table III). When two peptides in one sample were positive, the sample was positive. The sensitivity 

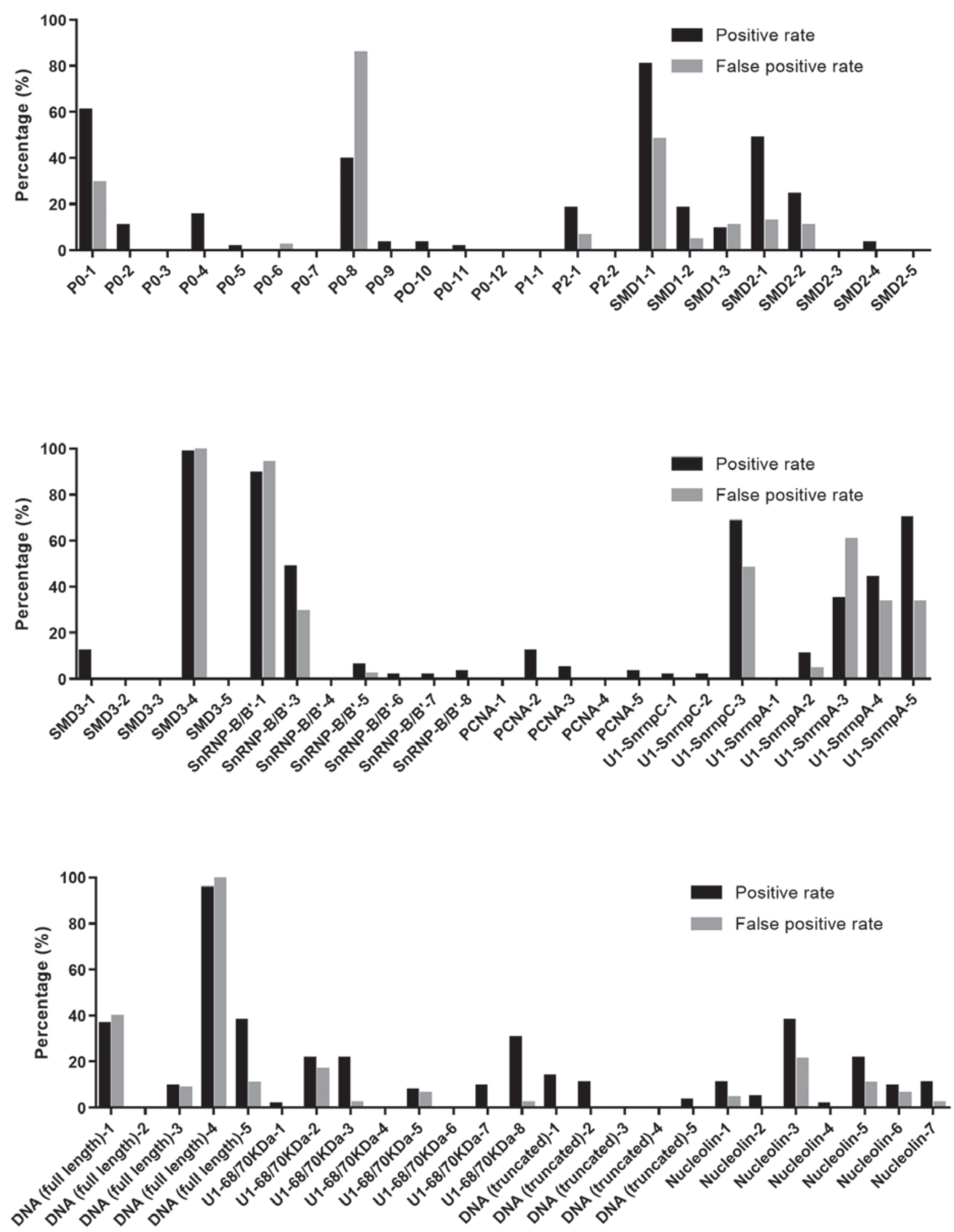

Figure 2. The positive rate and false positive rate of 73 peptides.

Table II. Comparison between ELISA and peptide microarray.

\begin{tabular}{lcccccr}
\hline & \multicolumn{2}{c}{ Intact antigens } & & \multicolumn{2}{c}{ Peptide microarray } & \\
\cline { 2 - 3 } Antigens & Sensitivity & Specificity & & Sensitivity & Specificity & Related \\
\hline Sm & 20.1 & 100 & & 57.6 & 79.1 & 0.85 \\
RNP & 41.8 & 100 & & 51.5 & 91.6 & 0.88 \\
\hline
\end{tabular}


A

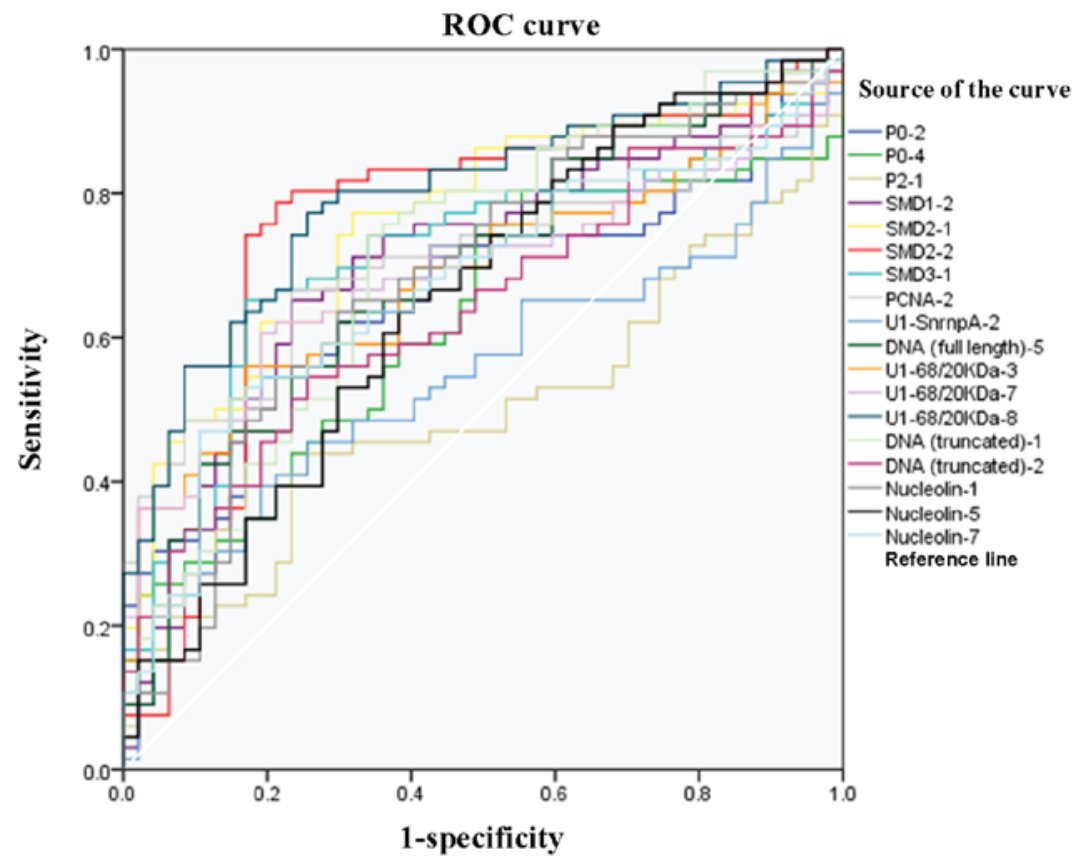

B

Area under the curve

\begin{tabular}{|c|c|c|c|c|c|}
\hline \multirow[t]{2}{*}{ Test result variable(s) } & \multirow[t]{2}{*}{ Area } & \multirow[t]{2}{*}{ Std. error ${ }^{a}$} & \multirow[t]{2}{*}{$\begin{array}{l}\text { Asymptotic } \\
\text { sig. }^{\text {b }}\end{array}$} & \multicolumn{2}{|c|}{$\begin{array}{c}\text { Asymptotic } 95 \% \text { confidence } \\
\text { interval }\end{array}$} \\
\hline & & & & Lower bound & Upper bound \\
\hline $\mathrm{P} 0-2$ & 0.662 & 0.051 & 0.003 & 0.563 & 0.762 \\
\hline P0-4 & 0.622 & 0.053 & 0.028 & 0.518 & 0.725 \\
\hline P2-1 & 0.498 & 0.054 & 0.977 & 0.392 & 0.605 \\
\hline SMD1-2 & 0.701 & 0.050 & 0.000 & 0.603 & 0.799 \\
\hline SMD2-1 & 0.760 & 0.045 & 0.000 & 0.671 & 0.848 \\
\hline SMD2-2 & 0.756 & 0.050 & 0.000 & 0.658 & 0.853 \\
\hline SMD3-1 & 0.713 & 0.049 & 0.000 & 0.617 & 0.810 \\
\hline PCNA-2 & 0.704 & 0.049 & 0.000 & 0.608 & 0.800 \\
\hline U1-SnrnpA-2 & 0.550 & 0.054 & 0.370 & 0.444 & 0.656 \\
\hline DNA (full length)-5 & 0.691 & 0.050 & 0.001 & 0.593 & 0.788 \\
\hline $\mathrm{U} 1-68 / 20 \mathrm{kDa}-3$ & 0.685 & 0.050 & 0.001 & 0.587 & 0.782 \\
\hline $\mathrm{U} 1-68 / 20 \mathrm{kDa}-7$ & 0.689 & 0.050 & 0.001 & 0.592 & 0.787 \\
\hline U1-68/20 kDa-8 & 0.795 & 0.042 & 0.000 & 0.713 & 0.877 \\
\hline DNA (truncated)-1 & 0.707 & 0.050 & 0.000 & 0.610 & 0.804 \\
\hline DNA (truncated)-2 & 0.639 & 0.052 & 0.012 & 0.538 & 0.740 \\
\hline Nucleolin-1 & 0.684 & 0.051 & 0.001 & 0.584 & 0.784 \\
\hline Nucleolin-5 & 0.651 & 0.053 & 0.006 & 0.548 & 0.754 \\
\hline Nucleolin-7 & 0.672 & 0.051 & 0.002 & 0.573 & 0.772 \\
\hline
\end{tabular}

a Under the nonparametric assumption

b Null hypothesis: true area $=0.5$

Figure 3. The ROC curve and statistical analysis of detection data by 18 peptides. (A) ROC curve. Sensitivity and 1-specificity represent the true positive rate and false positive rate, respectively. (B) The area under the curves.

Table III. Diagnostic results of SLE using 18 peptides.

\begin{tabular}{lrcc}
\hline Detection & SLE & Healthy & Total \\
\hline Positive detection & 86 & 16 & 102 \\
Negative detection & 34 & 94 & 128 \\
Total & 120 & 110 & \\
\hline
\end{tabular}

of peptide microarray in the diagnosis of SLE was $71.6 \%$, and the specificity was $85.5 \%$.

\section{Discussion}

Autoantibodies are an important feature of autoimmune diseases and are important indicators of disease diagnosis and 
progression monitoring. Autoantibodies can be detected by intact antigens, but the target epitopes by each autoantibody cannot be accurately identified. In clinic, the precise identification of autoantibodies and the detection of combining epitopes is of great significance in accurate diagnosis and treatment. The present study uses peptide microarray technology to detect the autoantibodies in peripheral blood of SLE patients. The findings suggested epitopes recognized by autoantibodies of individual SLE patients was different. As individual patient has a specific autoantibody spectrum, detection of autoantibodies by peptide microarray is useful for diagnosis of SLE.

The use of autoantigens to detect autoantibodies is an important diagnostic technique for autoimmune diseases. However, all the current detection methods have limited by poor positive rates, sensitivity. Although the sensitivity of ANA in SLE diagnosis is as high as $97-100 \%$, its specificity is only $10-40 \%$. Moreover, when ANA is negative, it cannot rule out the SLE completely, suggesting the diagnosis by ANA should take account the clinical conditions. The specificity of anti-rRNP antibody in SLE is $20-30 \%$ (4). The specificity of anti-SSA antibody in neonatal patients with lupus erythematosus is $100 \%(27,28)$. The anti-dsDNA antibody are closely associated with SLE, which shown a high specificity in the diagnosis of SLE (29). However, excessive free DNA antigens in the serum will influent the diagnosis of SLE in some patients since they could combine with anti-dsDNA antibodies $(29,30)$. It was also demonstrated that the anti-Sm antibodies, anti-nucleosome antibody could use in the diagnosis of SLE. Although the positive rate of anti-Sm antibody for SLE was $98 \%$, its sensitivity was only $20-30 \%(3,5,31,32)$. In addition, the detection of antibodies by ELISA is not only inefficient but also costly, which is becoming a major obstacle to the early diagnosis of SLE.

Compared with the intact antigen, we found that peptide microarray results were negative when the intact antigen detection was negative. If the intact antigen test result is positive, at least one peptide detection was positive. Zhu et al designed arrays containing synthetic peptides and molecular modified protein which being utilized for identification of autoantibodies targeting to special antigenic epitopes (33). Our results showed the sensitivity and specificity of the combination of 73 peptides in the diagnosis of SLEs can reach 96.9 and $93.8 \%$, but any single index cannot meet the clinical needs. Therefore, the combined detection of multiple indictors by peptide microarray has important value in the detection of SLE.

In the present study, the linear epitopes of 14 antigens were predicted by antigen epitope prediction software and an optimal set of epitopes for SLE diagnosis was obtained. Although the current epitope prediction software could predict the spatial epitopes, short peptide could not be simulated due to the far away between amino acid in space epitope. Nowadays, the peptide microarray could not be used to detect the autoantibody by identified spatial epitope. This is a flaw in this project. In addition, we found that the spectrum of autoantibodies varied considerably among different SLE patients. Therefore, a large number of samples are needed to accurately calculate the positive rate of each locus, which is another defect of the present study. Constructing a map of each Person's epitope and analyzing his association with disease progression are our future research direction.

\section{Acknowledgements}

The present study was supported by the National Natural Science Foundation of China (grant no. 320.6750.16039) and President Foundation of Nanfang Hospital, Southern Medical University (grant no. 2017C033).

\section{References}

1. Groot N, de Graeff N, Avcin T, Bader-Meunier B, Brogan P, Dolezalova P, Feldman B, Kone-Paut I, Lahdenne P, Marks SD, et al: European evidence-based recommendations for diagnosis and treatment of childhood-onset systemic lupus erythematosus: The SHARE initiative. Ann Rheum Dis 76: 1788-1796, 2017.

2. Leal GN, Diniz MF, Brunelli J, Lianza AC, Sallum AM and Silva CA: What are the benefits of two-dimensional speckle tracking echocardiography for diagnosis and treatment follow-up of childhood-onset systemic lupus erythematosus myocarditis? Rev Assoc Med Bras (1992) 62: 490-493, 2016.

3. Tunnicliffe DJ, Singh-Grewal D, Kim S, Craig JC and Tong A: Diagnosis, monitoring, and treatment of systemic lupus erythematosus: A systematic review of clinical practice guidelines. Arthritis Care Res 67: 1440-1452, 2015.

4. Fu SM, Deshmukh US and Gaskin F: Pathogenesis of systemic lupus erythematosus revisited 2011: End organ resistance to damage, autoantibody initiation and diversification and HLA-DR. J Autoimmun 37: 104-112, 2011.

5. Kuhn A, Bonsmann G, Anders HJ, Herzer P, Tenbrock K and Schneider M: The diagnosis and treatment of systemic lupus erythematosus. Dtsch Arztebl Int 112: 423-432, 2015.

6. Zhao J, Wang K, Wang X, Li T, Guo L, Gu L, Chen Z, Sun F, Wang H, Li J, et al: The performance of different anti-dsDNA autoantibodies assays in Chinese systemic lupus erythematosus patients. Clin Rheumatol 37: 139-144, 2018.

7. Ruzieh M, Batizy L, Dasa O, Oostra C and Grubb B: The role of autoantibodies in the syndromes of orthostatic intolerance: A systematic review. Scand Cardiovasc J 51: 243-247, 2017.

8. Ma WT, Chang C, Gershwin ME and Lian ZX: Development of autoantibodies precedes clinical manifestations of autoimmune diseases: A comprehensive review. J Autoimmun 83: 95-112, 2017.

9. Hu C, Li M, Liu J, Qian J, Xu D, Zhang S, Li P, Zhao J, Tian X and Zeng X: Anti-SmD1 antibodies are associated with renal disorder, seizures, and pulmonary arterial hypertension in Chinese patients with active SLE. Sci Rep 7: 7617, 2017.

10. Bai Y, Tong Y, Liu Y and Hu H: Self-dsDNA in the pathogenesis of systemic lupus erythematosus. Clin Exp Immunol 191: 1-10, 2018.

11. Arif Z, Neelofar K, Tarannum I, Arfat MY, Ahmad S, Zaman A, Khan MA, Badar A, Islam SN2 and Iqubal MA: SLE autoantibodies are well recognized by peroxynitrite-modified-HSA: Its implications in the pathogenesis of SLE. Int J Biol Macromol 106: 1240-1249, 2018

12. Agmon-Levin N, Dagan A, Peri Y, Anaya JM, Selmi C, Tincani A, Bizzaro N, Stojanovich L, Damoiseaux J, Cohen Tervaert JW, et al: The interaction between anti-Ro/SSA and anti-La/SSB autoantibodies and anti-infectious antibodies in a wide spectrum of auto-immune diseases: Another angle of the autoimmune mosaic. Clin Exp Rheumatol 35: 929-935, 2017.

13. Zhang B, Jarrell JA, Price JV, Tabakman SM, Li Y, Gong M, Hong G, Feng J, Utz PJ and Dai H: An integrated peptide-antigen microarray on plasmonic gold films for sensitive human antibody profiling. PLoS One 8: e71043, 2013.

14. Haddon DJ, Diep VK, Price JV, Limb C, Utz PJ and Balboni I: Autoantigen microarrays reveal autoantibodies associated with proliferative nephritis and active disease in pediatric systemic lupus erythematosus. Arthritis Res Ther 17: 162, 2015.

15. Price JV, Tangsombatvisit S, Xu G, Yu J, Levy D, Baechler EC, Gozani O, Varma M, Utz PJ and Liu CL: On silico peptide microarrays for high-resolution mapping of antibody epitopes and diverse protein-protein interactions. Nat Med 18: 1434-1440, 2012. 
16. Price JV, Haddon DJ, Kemmer D, Delepine G, Mandelbaum G, Jarrell JA, Gupta R, Balboni I, Chakravarty EF, Sokolove J, et al: Protein microarray analysis reveals BAFF-binding autoantibodies in systemic lupus erythematosus. J Clin Invest 123: 5135-5145, 2013.

17. Balboni I, Niewold TB, Morgan G, Limb C, Eloranta ML, Rönnblom L, Utz PJ and Pachman LM: Interferon- $\alpha$ induction and detection of anti-ro, anti-la, anti-sm, and anti-rnp autoantibodies by autoantigen microarray analysis in juvenile dermatomyositis. Arthritis Rheum 65: 2424-2429, 2013.

18. Gori A, Cretich M, Vanna R, Sola L, Gagni P, Bruni G, Liprino M, Gramatica F, Burastero S and Chiari M: Multiple epitope presentation and surface density control enabled by chemoselective immobilization lead to enhanced performance in IgE-binding fingerprinting on peptide microarrays. Anal Chim Acta 983: 189-197, 2017.

19. De Plano LM, Carnazza S, Messina GML, Rizzo MG Marletta G and Guglielmino SPP: Specific and selective probes for Staphylococcus aureus from phage-displayed random peptide libraries. Colloids Surf B Biointerfaces 157: 473-480, 2017.

20. Kafi MA, Cho HY and Choi JW: Engineered peptide-based nanobiomaterials for electrochemical cell chip. Nano Converg 3 : 17, 2016.

21. Maksimov P, Zerweck J, Maksimov A, Hotop A, Gross U, Spekker K, Däubener W, Werdermann S, Niederstrasser O, Petri E, et al: Analysis of clonal type-specific antibody reactions in Toxoplasma gondii seropositive humans from Germany by peptide-microarray. PLoS One 7: e34212, 2012.

22. Zhong L, Coe SP, Stromberg AJ, Khattar NH, Jett JR and Hirschowitz EA: Profiling tumor-associated antibodies for early detection of non-small cell lung cancer. J Thorac Oncol 1: 513-519, 2006

23. Woodard KM and Chapman CJ: Lung cancer-can autoantibodies provide an aid to diagnosis? Expert Opin Med Diagn 2: 911-923, 2008.

24. Chapman CJ, Murray A, McElveen JE, Sahin U, Luxemburger U, Türeci $\mathrm{O}$, Wiewrodt $\mathrm{R}$, Barnes $\mathrm{AC}$ and Robertson JF: Autoantibodies in lung cancer: Possibilities for early detection and subsequent cure. Thorax 63: 228-233, 2008.
25. Saleh J, Brunner C, Gölzer R, Nastainczyk W and Montenarh M: p53 autoantibodies from patients with head and neck cancer recognise common epitopes on the polypeptide chain of $\mathrm{p} 53$. Cancer Lett 233: 48-56, 2006.

26. Saleh J, Kreissler-Haag D and Montenarh M: p53 autoantibodies from patients with colorectal cancer recognize common epitopes in the N- or C-terminus of p53. Int J Oncol 25: 1149-1155, 2004.

27. de Jesus GR, Mendoza-Pinto C, de Jesus NR, Dos Santos FC, Klumb EM, Carrasco MG and Levy RA: Understanding and managing pregnancy in patients with lupus. Autoimmune Dis 2015: 943490,2015

28. Marder W, Ganser MA, Romero V, Hyzy MA, Gordon C, McCune WJ and Somers EC: In utero azathioprine exposure and increased utilization of special educational services in children born to mothers with systemic lupus erythematosus. Arthritis Care Res 65: 759-766, 2013

29. Crampton SP, Morawski PA and Bolland S: Linking susceptibility genes and pathogenesis mechanisms using mouse models of systemic lupus erythematosus. Dis Model Mech 7: 1033-1046, 2014.

30. Gottschalk TA, Tsantikos E and Hibbs ML: Pathogenic inflammation and its therapeutic targeting in systemic lupus erythematosus. Front Immunol 6: 550, 2015.

31. Ramos-Casals M, Sanz I, Bosch X, Stone JH and Khamashta MA: B-cell-depleting therapy in systemic lupus erythematosus. Am J Med 125: 327-336, 2012.

32. Ching KH, Burbelo PD, Tipton C, Wei C, Petri M, Sanz I and Iadarola MJ: Two major autoantibody clusters in systemic lupus erythematosus. PLoS One 7: e32001, 2012.

33. Zhu H, Luo H, Yan M, Zuo X and Li QZ: Autoantigen microarray for high-throughput autoantibody profiling in systemic lupus erythematosus. Genomics Proteomics Bioinformatics 13: 210-218, 2015.

This work is licensed under a Creative Commons Attribution-NonCommercial-NoDerivatives 4.0 International (CC BY-NC-ND 4.0) License. 